\title{
Original
}

\section{The Ability of Xylitol Containing Gum with Calcified Seaweed in Preventing Demineralization of Tooth Surfaces}

\author{
Yasuo Miake ${ }^{1)}$, Shinji Nozue ${ }^{2)}$, Mitsuko Moriguchi ${ }^{1)}$, Takaki Yamazaki ${ }^{1)}$, \\ Takashi Sawada ${ }^{1)}$ and Takaaki Yanagisawa ${ }^{1)}$
}

\author{
1) Department of Ultrastructural Science, Oral Science Center, Tokyo Dental College,Mihama-ku, Chiba, Japan \\ ${ }^{2)}$ Chiba Hospital,Tokyo Dental College, Mihama-ku, Chiba, Japan \\ (Accepted for publication, July 19, 2011)
}

\begin{abstract}
The incidence of root caries and hyperesthesia in elderly people tend to increase with increasing age. This can be prevented by enhancing the root surfaces against aciduric bacteria. In order to prevent root caries, a chewing gum containing calcified seaweed rich in $\mathrm{Ca}, \mathrm{Mg}, \mathrm{Na}, \mathrm{F}$ and $\mathrm{P}$ was created. A dentin block was made from the cervical part of the third molar after removing the cementum. The dentin blocks were immersed in remineralizing solution with extract of the gum with or without calcified seaweed for 2 weeks. The dentin blocks were immersed in demineralizing solution for 6 hours and acid resistance was evaluated after. Demineralization was evaluated by CMR image, demineralization depth (Ld) and mineral loss quantity $(\triangle \mathrm{Z})$ by image analysis, qualitative analysis by EPMA and the surface structure with the SEM. CMR image analysis revealed that the region immersed in aciduric solution had less quantity of demineralization than the region which was not immersed. A significant difference in $\mathrm{Ld}$ and $\triangle \mathrm{Z}$ of the demineralization area after the aciduric treatment between the solution with calcified seaweed and the solution without aciduric treatment $(p<0.05)$ was observed. Levels of Ca, P and Mg were detected in EPMA except for F. In SEM, the dentinal tubules of the demineralized region without aciduric treatment was enlarged which was not seen in demineralized region after aciduric treatment. The results indicate that the chewing gum with calcified seaweed is effective in increasing dentinal acid resistance.
\end{abstract}

Key words: Calcified seaweed, Dentin, Aciduric enhancement, Xylitol

\section{Introduction}

The increase in the awareness in oral hygiene improved the percentage elderly dentulous patients. However, due to gingival recession and periodontal disease brought about by aging, many cases of hyperesthesia and root caries are observed on exposed root after gingival recession ${ }^{1}$. Removal of necrotic cementum on the exposed root surface and aciduric improvement of the exposed dentin are required to prevent root caries formation.

Enamel surface undergoes repeated demineralization and remineralization and the balance is maintained or affected by saliva ${ }^{2}$. Eating causes the saliva to become acidic but saliva provides a buffering action which returns the oral environment immediately to neutral ${ }^{3,4)}$ and has bactericidal activity against cariogenic bacteria ${ }^{5,6)}$. Supersaturation by minerals like calcium (Ca) and phosphate (P) is essential in suppressing the onset of

Correspondence to: Dr.Yasuo Miake, DDS, PhD, Department of Ultrastructural Science, Oral Science Center, Tokyo Dental College, 1-2-2 Masago, Mihama-ku, Chiba 261-8502, Japan. Tel No: +8143-270-3755, Fax No: +81-43-270-3756,E-mail: miake@tdc.ac.jp demineralization and inducing remineralization. In addition, a small amount of fluorine (F) is also needed ${ }^{7,8)}$. Therefore, saliva plays an important role in caries prevention.

Fluoride and xylitol are used in enhancing the effect of saliva ${ }^{9-}$ ${ }^{13)}$, especially $\mathrm{F}$ which is highly effective in the prevention and recovery of initial carious lesions ${ }^{9}$. However, fluoride is not a food additive so it cannot be directly added to it. There are only few foods that contain large amounts of $\mathrm{F}^{14)}$ but in our previous study ${ }^{15}$, calcified seaweed contains large amounts of Ca, P and F, which may be effective in remineralization process.

In this study, the effectiveness of a chewing gum with calcified seaweed against demineralization was investigated

\section{Materials and Methods}

\section{Preparation of dentin blocks}

A total of 20 human third molars extracted due to pericoronitis from patients 20-40 years old were used in the study. The samples were preserved in $10 \%$ formalin solution after extraction. The Ethics Committee of Tokyo Dental College, Ethical Clearance 
Number 189, approved the experiment. The cervical cementum was removed using wet abrasive paper (\#4000) and 40 dentin blocks were prepared.

\section{Calcified seaweed}

Calcified seaweed (Aquamineral $\mathrm{T}^{\circledR}$ : Biocon Japan Ltd.) was obtained from dead calcareous deposits, which accumulated at the bottom of the sea. The calcified seaweed contains 34.0\% Ca, 3.14\% $\mathrm{Mg}, 0.56 \% \mathrm{P}, 0.24 \% \mathrm{Na}, 0.11 \% \mathrm{~F}$ and others. Due to its poor solubility, calcified seaweed was dissolved in acid. The solution was neutralized and freeze-dried to obtain a powder form.

\section{Chewing gum for experiment}

Chewing gum for the experiment was prepared by Lotte Co. Ltd. The chewing gum contains 36\% xylitol, 2\% citric acid and others. Two kinds of chewing gums were made in which one kind contains $1.6 \%$ calcified seaweed and the other was without calcified seaweed. Remineralizing solutions and extracts of the gum with or without calcified seaweed were made. The remineralizing solution was composed of $1 \mathrm{mM} \mathrm{CaCl}, 0.6 \mathrm{mM} \mathrm{KH}_{2} \mathrm{PO}_{4}$ and $100 \mathrm{mM}$ $\mathrm{NaCl}$ and $\mathrm{KOH}$ solution was used to adjust the $\mathrm{pH}$ to 7.2.

Chewing gum extracts were prepared using remineralization solution as follows. Each chewing gum sample was broken into pieces and $30 \mathrm{~g}$ was measured. The gum extracts were prepared from these fragments using $150 \mathrm{ml}$ remineralizing solution at $60{ }^{\circ} \mathrm{C}$ for $5 \mathrm{~min}$ and re-extracted again with a new solution. This gum extract solution was adjusted to a $\mathrm{pH}$ of 7.2 with $\mathrm{KOH}$. Those groups immersed in remineralizing solution with calcified seaweed was called M-solution, those without calcified seaweed was called $\mathrm{N}$-solution and those with remineralizing solution only was called R-solution.

\section{Aciduric experiment}

Each block was covered with sticky dental wax, leaving a $3 \mathrm{x}$ $4 \mathrm{~mm}$ uncovered surface. Each of the 10 blocks suspended by threads was immersed in $300 \mathrm{ml}$ remineralizing solutions at $37^{\circ} \mathrm{C}$ for 2 weeks. The solutions used for each group was replaced every week. After 2 weeks, the blocks were washed with distilled water, dried and immersed in xylene for dewaxing. Each block was re-covered with sticky dental wax, leaving half of the region immersed in a solution and the other region was not immersed. These blocks were immersed in $50 \mathrm{ml} /$ block demineralizing solution (acetate buffer solution $\mathrm{pH} 4.0$ ) at $37^{\circ} \mathrm{C}$ for $6 \mathrm{~h}$. After immersion, the blocks were washed with distilled water, dried and immersed in xylene for dewaxing.

\section{Contact microradiogram (CMR) examination}

Samples were dehydrated in graded ethanol and embedded in polyester resin (Rigolac; Nisshin EM Co. Ltd, Tokyo, Japan). Ground sections (100 $\mu \mathrm{m}$ thick) were prepared from dentin blocks to include the vertical aspect of the experimental surface. CMR images of ground sections were taken using soft X-ray generator (Softex CMR-3; Softex Co., Ltd, Tokyo, Japan) with $20 \mu \mathrm{m} \mathrm{Ni}$ filter operated at an accelerating voltage of $10 \mathrm{kV}$ and a specimen current of $3 \mathrm{~mA}$ for $7 \mathrm{~min}$ with $\mathrm{Cu}-\mathrm{K} \alpha$. An aluminum step wedge (20 $\mu \mathrm{m} \times 20$ steps) was placed on the X-ray glass film plate (HRPSN-2; Konica Minolta, Tokyo, Japan) with the sample for the image analysis. The glass film plate was developed (D-19; Kodak, USA) for $5 \mathrm{~min}$ at $20^{\circ} \mathrm{C}$, rinsed with tap water and then fixed (Fujifix; Fuji Film, Tokyo, Japan) for 5 min at $20^{\circ} \mathrm{C}$.

\section{Image analysis}

CMR images were taken using Image Analyze System (HC2500/OL; Olympus, Tokyo, Japan: HDS-N1; Hiroya, Tokyo, Japan). Each digital image was made in 256 level grey scale with a width of $50 \mu \mathrm{m}$ and depth of $300 \mu \mathrm{m}$ (from resin base to intact dentin). The demineralization rate (mineral loss value; $\triangle \mathrm{Z}$ ) for each definite area was calculated in terms of aluminum equivalence by setting the photographic density of film (not involving the sample) to $0 \%$ and that of intact dentin to $100 \%$. Lesion depth (Ld) was defined as the distance from the virtual surface to the location in the lesion where the mineral content was larger than $95 \%$ of the mineral content in sound dentin. The original surface position became lower by demineralization experiment therefore the surface before the demineralization experiment was a virtual surface. Ld and $\triangle \mathrm{Z}$ were measured from this virtual surface to the bottom of demineralized layer (Figure 1). Three areas on each sample were measured and the mean was obtained. The aciduric ratio was calculated from the values obtained.

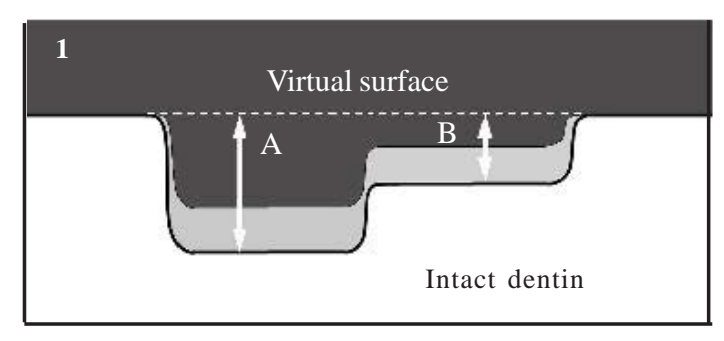

Figuer 1. Schema of CMR image. The dotted line shows the dentinal virtual surface. The arrows show the measuring range of demineralized area (A) and demineralized area after immersion (B).

\section{Electron probe microanalyzer (EPMA) examination}

After coating the ground sections with a thin layer of carbon, qualitative and aspect analysis of $\mathrm{Ca}, \mathrm{P}, \mathrm{Mg}$ and $\mathrm{F}$ ions were carried out using EPMA (JXA-8200; JEOL, Tokyo, Japan).

\section{Scanning electron microscope (SEM) examination}

Samples were dehydrated in graded ethanol and were replaced by t-butyl alcohol. Freeze-drying was conducted in a freeze dryer 
Yasuo Miake et al.:Ability of Calcified Seaweed in Preventing Demineralization
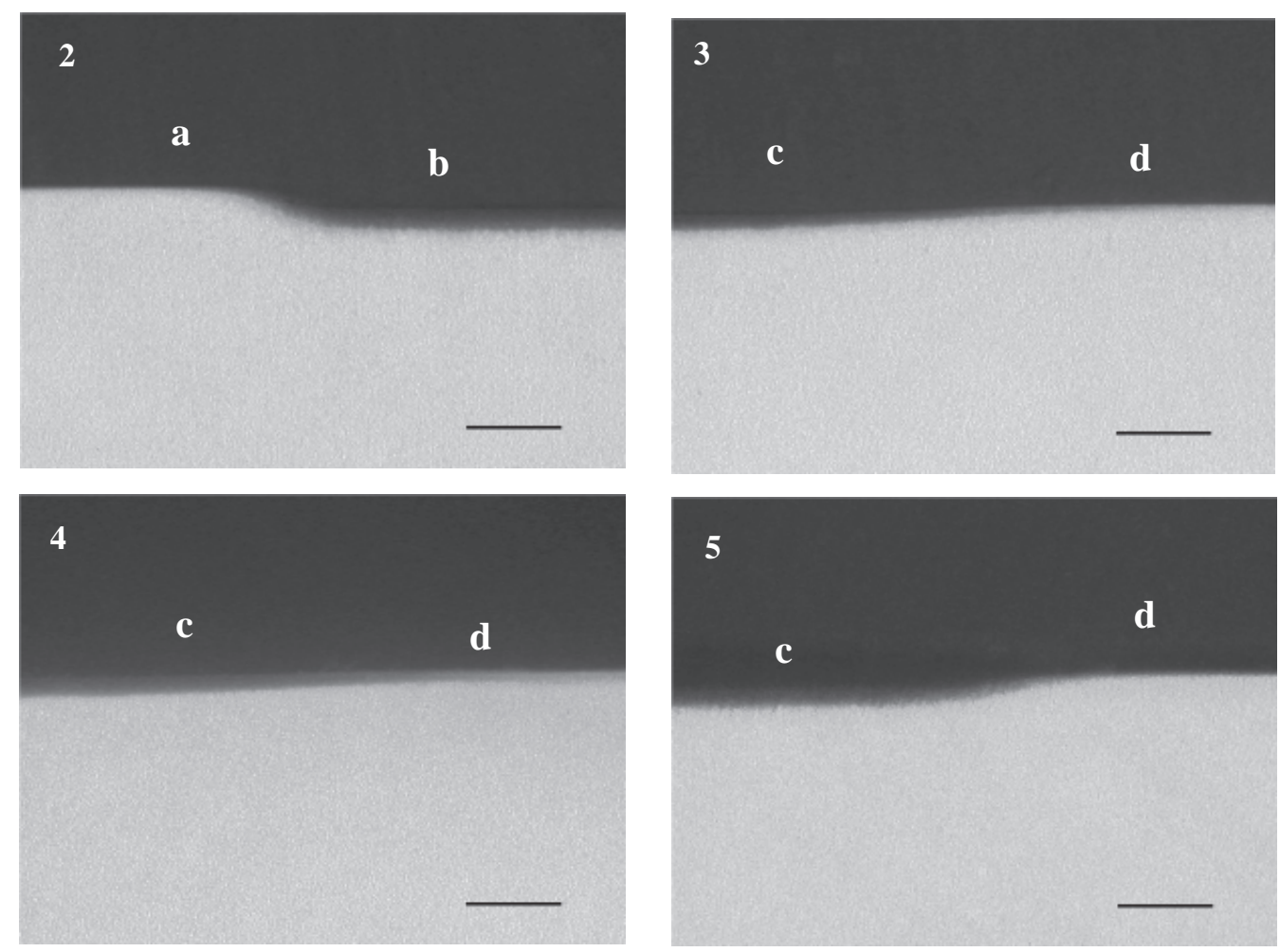

Figure 2. Non-immersion area (a), demineralized area (b) are shown. Scale bar=100 $\mu \mathrm{m}$

Figure 3. Samples immersed in M-solution. Demineralized area after immersion (c) and immersion area (d) are shown. Scale bar $=100 \mu \mathrm{m}$

Figure 4. Samples immersed in N-solution. Scale bar $=100 \mu \mathrm{m}$

Figure 5. Samples immersed in R-solution. Demineralized area after immersion (c) and immersion area (d) are shown.

Scale bar $=100 \mu \mathrm{m}$

(ID-2, Eiko, Tokyo). The samples were then sputter coated with $\mathrm{Au}-\mathrm{Pd}$, and the surface structure was examined under a field emission SEM (JSM-6340F, JEOL, Tokyo). The accelerating voltage was $15 \mathrm{kV}$.

The observation mentioned above followed a non-immersion area (control area), demineralized area, demineralized area after immersion and immersion area.

\section{CMR images}

In all samples, the outer surface of demineralized dentin (Figure 2-5, b and c) underwent shrinkage and broke down moderately compared to undemineralized part (Figure 2-5, a and d). The demineralized area (Figure 2, b) was more than the demineralized area after immersion treatment (Figure 3-5, c). The surface remineralization image of the demineralized layer was not seen in most samples.

\section{Image analysis}

The lesion depth (Ld: $\mu \mathrm{m})$ on each CMR image and mineral loss value $(\triangle \mathrm{Z}$ : vol\% $\cdot \mu \mathrm{m})$ were measured. Because the original surface was removed by demineralization, $\mathrm{Ld}$ and $\triangle \mathrm{Z}$ were measured from the virtual surface to the bottom of demineralized layer (Figure 1). With the exception of the sample wherein the wax was removed during experiment, measurements from 7 samples in each group were obtained.

Table 1 shows the results of $\mathrm{Ld}$ and $\triangle \mathrm{Z}$ where $\mathrm{A}$ is demineralized area, $\mathrm{B}$ is demineralized area after immersion treatment and $\mathrm{C}$ is aciduric ratio.

A significant difference in $\mathrm{Ld}$ and $\triangle \mathrm{Z}$ was obtained between $\mathrm{A}$ and $B(p<0.01)$ but not for those in N-solution $(p<0.05)$. For Ld of $\mathrm{B}$, a significant difference was not obtained between M-solution, $\mathrm{N}$-solution and R-solution. For $\triangle \mathrm{Z}$ of $\mathrm{B}$, a significant difference was obtained between M-solution and N-solution ( $p<0.05)$, but was not obtained between M-solution and R-solution or R-solution and $\mathrm{N}$-solution. The aciduric ratio had no significant difference, but M-solution has the largest mean and N-solution was the least.

From these results, the acid resistance increased in this order: $\mathrm{N}$-solution $<$ R-solution $<$ M-solution.

\section{EPMA analysis}

In the surface region of all samples, Ca, $\mathrm{P}$ and $\mathrm{Mg}$ were detected in qualitative analysis, but $\mathrm{F}$ was not detected. In aspect analysis, the distribution density of $\mathrm{Ca}$ and $\mathrm{Mg}$ decreased in demineralized 
Table 1. Results of Ld and $\triangle \mathrm{Z}$

\begin{tabular}{|c|c|c|c|c|c|c|}
\hline & \multicolumn{2}{|l|}{$\mathrm{Ld}(\mu \mathrm{m})$} & \multirow{2}{*}{$\begin{array}{l}\mathrm{Ld}(\%) \\
\mathrm{C}\end{array}$} & \multicolumn{2}{|c|}{$\triangle \mathrm{Z}(\mathrm{vol} \% \cdot \mu \mathrm{m})$} & \multirow{2}{*}{$\begin{array}{l}\triangle \mathrm{Z}(\%) \\
\mathrm{C}\end{array}$} \\
\hline & $\mathrm{A}$ & $\mathrm{B}$ & & $\mathrm{A}$ & $\mathrm{B}$ & \\
\hline M-solution & $39.80 \pm 4.77$ & $28.64 \pm 5.01$ & $27.84 \pm 10.52$ & $2980 \pm 270$ & $1792 \pm 291$ & $39.50 \pm 11.14$ \\
\hline N-solution & $49.37 \pm 12.91$ & $32.56 \pm 9.47$ & $33.02 \pm 14.24$ & $3540 \pm 1026$ & $2477 \pm 853$ & $29.70 \pm 14.50$ \\
\hline R-solution & $39.27 \pm 6.88$ & $27.64 \pm 8.19$ & $28.42 \pm 21.12$ & $3208 \pm 627$ & $2081 \pm 773$ & $32.70 \pm 27.49$ \\
\hline
\end{tabular}

The table shows Ld (lesion depth) and $\triangle \mathrm{Z}$ (mineral loss value). A: demineralized area, B: demineralized area after immersion. C: aciduric ratio. Data represent the mean \pm S.D. $(n=7)$
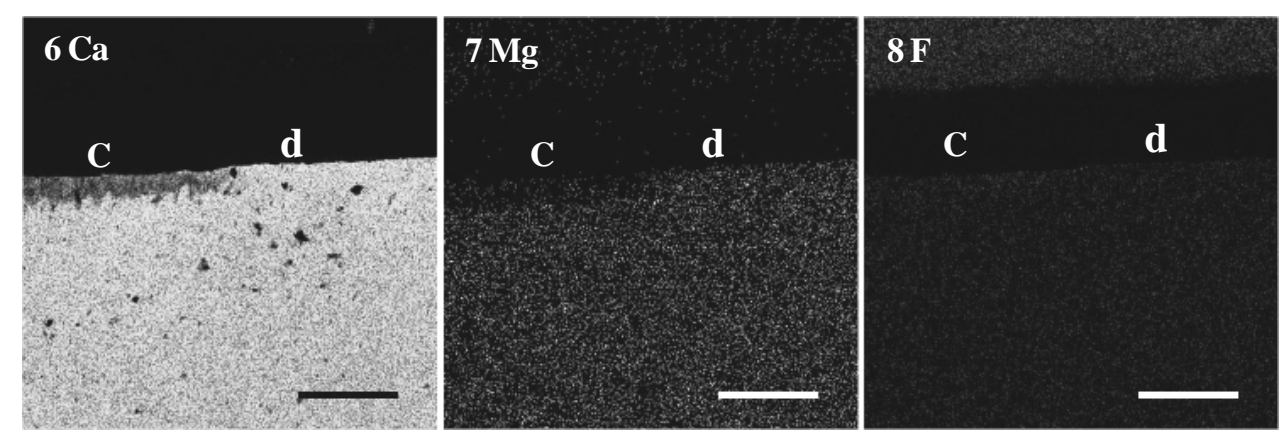

Figures 6, 7 and 8. Aspect analysis results of the M-solution immersion case are shown. Analysis of Ca (Figure 6), Mg (Figure 7) and F (Figure 8) in the same location is shown. Demineralized area after immersion (c) and immersion area (d). Scale bar $=50 \mu \mathrm{m}$
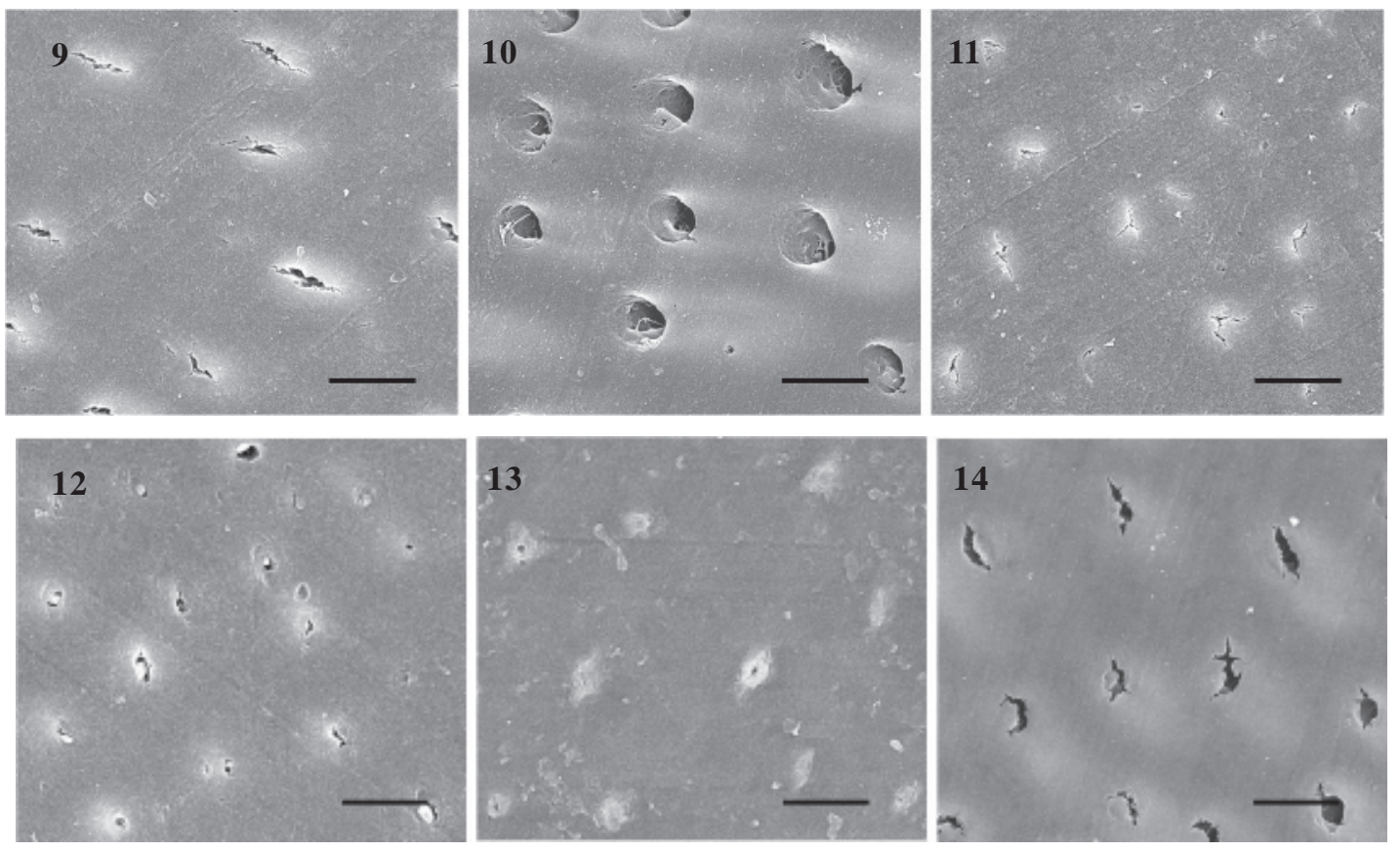

Figure 9. Non-immersion surface. Scale bar $=5 \mu \mathrm{m}$

Figure 10. Demineralized surface. Scale bar $=5 \mu \mathrm{m}$

Figure 11. Immersion surface. Scale bar $=5 \mu \mathrm{m}$

Figure 12. Demineralized surface after immersion to M-solution. Scale bar=5 $\mu \mathrm{m}$

Figure 13. Demineralized surface after immersion to N-solution. Scale bar $=5 \mu \mathrm{m}$

Figure 14. Demineralized surface after immersion to R-solution. Scale bar $=5 \mu \mathrm{m}$ 
Yasuo Miake et al.:Ability of Calcified Seaweed in Preventing Demineralization

area after immersion treatment (Figure 6, 7) although F was not detected (Figure 8). Between each aciduric experiment, a conspicuous difference in distribution density was not seen.

\section{SEM images}

In non-immersion surface, the dentinal tubules were moderately closed, and shape like a crack was shown (Figures 9). On the other hand, the dentinal tubules became clear in demineralized surface, a large number of orbicular dentinal tubules were observed (Figure 10). In immersion surface, the dentinal tubules were almost closed and had a shape of small cracks (Figures 11). Almost the same finding was obtained in each experiment.

In samples demineralized after immersion to $\mathrm{M}$ - and $\mathrm{N}$-solution, most of the dentinal tubules were not enlarge and the image is similar to a non-demineralized surface (Figure 12, 13). However, the width of the crack expanded a little with demineralized surface after immersion to R-solution (Figure 14).

\section{Discussion}

\section{Result of CMR and image analysis}

The immersion and non-immersion dentin decreased the surface position by demineralization. This is because the dentinal inorganic substances were dissolved by demineralization and it was thought that shrinkage of the residual organic material occurred. When the demineralized area of immersed or non-immersed dentin was compared, the mineralization degree (Ld and $\triangle \mathrm{Z}$ ) of immersed dentin was higher than non-immersed dentin. This is due to the Ca and $\mathrm{P}$ present in the solution. The calcified seaweed contains large amounts of Ca and $\mathrm{P}$, which were added into the solution. Moreover, calcified seaweed contains more F which is known to function on crystal nucleation and crystal growth in small quantities. These ions act synergistically causing an increased in crystallinity or crystal growth. As a result, it is thought that dentinal acid resistance was increased in immersed dentin especially in M-solution.

Dentin crystals are known to contain carbonate and are highly soluble in acid ${ }^{16-18)}$. Therefore, it was thought that surface remineralization image of the demineralized layer was not seen. On the other hand, calcified seaweed contains lots of Mg. It has been reported that $\mathrm{Mg}$ increased its solubility to get into apatite crystal ${ }^{19,20)}$. There was the possibility that Mg affected the crystallinity in M-solution but aciduric enhancement occurred in this experiment and it seemed that the action of Ca, P and F may have been larger than the influence of $\mathrm{Mg}$.

\section{Result of EPMA}

In the samples immersed in $\mathrm{M}$-solution, $\mathrm{Ca}, \mathrm{P}$ and $\mathrm{Mg}$ were detected but $\mathrm{F}$ was not detected. Dentin mineral is made of Ca and $\mathrm{P}$, which also contain a small amount of $\mathrm{Mg}^{20)}$. In addition, calcified seaweed contains large amounts of $\mathrm{Mg}$ and $\mathrm{F}$. It seems that $\mathrm{Mg}$ was not originally from calcified seaweed as shown in aspect analysis. Although $\mathrm{F}$ was not detected, it was shown that the acid resistance of the M-solution was the best as indicated by image analysis. For this reason, $\mathrm{F}$ is considerably effective in very small amount, effective even below the detection limit of EPMA.

\section{Results of SEM}

When the non-immersion surface was compared with the solution immersion surface, the dentinal tubules of the immersion surface were closed. It was thought that a mineral deposit in solution immersion were responsible for the closure of the dentinal tubules. When this immersion surface was demineralized, enlargement of the dentinal tubules such as those in the demineralized surface of the non-treatment surface was not observed. Therefore, it is thought that relatively high aciduric crystals were deposited on the surface.

The results of the experiment indicate that calcified seaweed is effective in preventing tooth surface demineralization. Therefore, it is effective in preventing dental caries in exposed root.

\section{Acknowledgement}

This study was supported in part by the Oral Science Center, Tokyo Dental College and the chewing gum for experiment was provided by the Lotte Co. Ltd.

\section{Reference}

1. Imazato S, Ikebe K, Nokubi T, Ebisu S and Walls AW. Prevalence of root caries in a selected population of older adults in Japan. J Oral Rehabil 33: 137-143, 2006

2. Yanagisawa T, Miake Y, Saeki Y and Takahashi M. Remineralization in enamel caries and restoration of carious lesions by enhanced remineralization induced by saliva and xylitol. Dentistry in Japan 39: 208-215, 2003

3. Carey CM, Gregory TM, Tatevossian A and Vogel GM. The buffer capacity of single-site, resting, human dental-plaque fluid. Arch Oral Biol 33: 487-492, 1988

4. Dreizen S, Mann AW, JK Cline and Tom DS. The buffer capacity of saliva as a measure of dental caries. J Dent Res 25: 213-222, 1946

5. Hamon CB and Klebanoff SJ. A peroxidase-mediated, streptococcus mitis-dependent antimicrobial system in saliva. J Exp Med 137: 438-450, 1973

6. Bowen WH. Defense mechanisms in the mouth and their possible role in the prevention of dental caries. J Oral Pathol 3: 266-278, 1974

7. Shaw L, Murray JJ, Burchell CK and Best JS. Calcium and phosphorus content of plaque and saliva in relation to dental caries. Caries Res 17: 543-548, 1983

8. Shannon IL, Suddick RP, Dowd FJ Jr. Saliva. Composition and secretion. Monogr Oral Sci. 2: 1-103, 1974

9. Zimmer S, Jahn KR and Barthel CR. Recommendations for 
J.Hard Tissue Biology Vol. 20(2):87-92, 2011

the use of fluoride in caries prevention. Oral Health Prev

Dent 1: 45-51, 2003

10. Meyer-Lueckel H and Tschoppe P. Effect of fluoride gels and mouthrinses in combination with saliva substitutes on demineralised bovine enamel in vitro. J Dent 38: 641-647, 2010

11. Cochrane NJ, Cai F, Huq NL, Burrow MF and Reynolds EC. New approaches to enhanced remineralization of tooth enamel. J Dent Res 89: 1187-1197, 2010

12. Miake Y, Saeki Y, Takahashi M and Yanagisawa T. Remineralization effect of xylitol on demineralized enamel. J Electron Microsc 52: 471-476, 2003

13. Thaweboon S, Nakornchai S, Miake Y, Yanagisawa T, Thaweboon B, Soo-ampon S and Lexomboon D. Remineralization of enamel subsurface lesions by xylitol chewing gum containing funoran and calcium hydrogenphosphate. Southeast Asian J Trop Med Public Health 40: 345-353, 2009

14. McClure FJ. Fluorine in foods; survey of recent data. Public
Health Rep 64: 1061-1074, 1949

15. Yamazaki T, Miake Y, Ishikawa T, Hiruma N and Yanagisawa $\mathrm{T}$. The effect of calcified seaweed on remineralization of artificially demineralized dentin.J Hard Tissue Biology 20: 11-16, 2011

16. Okazaki M, Moriwaki Y, Aoba T, Doi Y and Takahashi J. Solubility behavior of $\mathrm{CO}_{3}$ apatites in relation to crystallinity. Caries Res 15: 477-483, 1981

17. Brudevold, F. Dental tissue factors in dental caries. Int Dent J 12: 496-507, 1962

18. Brudevold, F, Gardner DE and Smith FA. The distribution of fluoride in human enamel. J Dent Res 35: 420-429, 1956

19. Boulet M, Marier JR and Rose D. Effect of magnesium on formation of calcium phosphate precipitates. Arch Biochem Biophys 96: 629-636, 1962

20. Okazaki M, Takahashi J, Kimura H. Unstable behavior of magnesium-containing hydroxyapatites. Caries Res 20(4):324-331, 1986 